\title{
Duas escolas
}

João Mendes de Almeida Junior

\section{KANT}

Afirma KANT, na sua metafísica, que três são as faculdades cognoscitivas: a sensibilidade, o intelecto e a razão.

A sensibilidade tem como fórmas genéricas o espaço e o tempo, visto que as coisas não são por si estensas ou temporais, porém já aparecem sempre revestidas dessas fórmas a priori da nossa sensibilidade.

$\mathrm{O}$ intelecto tem como fórmas genéricas quatro classes de categorias, cada uma das quais se subdivide em três outras, isto é:

$10^{\circ}$ - a quantidade, que se subdivide em unidade, pluralidade, totalidade;

$2 .^{\circ}$ - a qualidade, que se subdivide em realidade, negação, limitação;

$3 .^{\circ}$ - relação, que se manifesta entre a causa e o efeito, entre a substância e o acidente e por açâo mútua;

4. - modalidade, que consiste na possibilidade ou impossibilidade, na iexistência e não existência e na nectessidade e contingência.

A razâo accede ás outras duas faculdades, coligindo os seus elementos esparsos ou divididos e acrescentando-lhes uma tríplice unidade, isto é, a psicológica ou do $₫ u$, a cosmológicia ou do mundo e a teológica ou de Deus.

KANT distingue a verdade em verdade teórica e verdade prática. 
Verdades teóricas são concepções que não influem sôbre a vontade humana, tais são estas: não ha efoito sem causa, todo o corpo está no tempo e no espiaço.

Verdades práticas são concepções que influem sôbre a vontade humana e cuja realização depende da ação desta vontade, tais são: busca tua felicidade, fazei o bem, evitai o mal.

As verdades teóricas são efeitos da razão pura; as verdades práticas são efeitos da razão prática.

Estas idéias, diz KANT, são formadas a priori, sem auxílio da experiência, porque não são as nossas idéias que se acomodam ás coisas, são as coisas que entram no molde das nossas idéias; nós ignoramos completamente o que póde ser a causa em si (nonmenos); nós a conhecemos apenas pela nossa maneira de a apresentar (phenomenos), a mesmos juizos sintéticos a priori, porque gozam da universalidade e da nectessidrade, por exemplo: $7+5=12$. Mas, nós não podemos afirmar nem negar que estes juizos universais representam alguma coisa que exista realmente fóra de nós. 0 critério da verdade, portanto, diz KaNT, é "a concórdia das nossas idéias consigo mesmas".

Daí os nomes de subjetivismo e criticismo dados ao sistema de KaNT.

KANT vê na razão prática dois conceitos a priori, o conceito da liberdiade e o conceito da obrigação.

Eis como ele concebe a liberdade:

O homem é afetado por móveis sensíveis; mas, póde ser determinado pela razão pura e independentemente desses móveis sensiveis; e só neste caso, se considera livre, porque, sómente então, opera segundo uma lei que ele compreende is que obriga quando é compreendida.

Eis como ele concebe a obrigação:

A idéia de obrigação decorre da idéia de liberdade, porque "a obrigação é a necessidade que imprime a uma ação livre um imperativo categórico da razão".

o impierativo é uma regra prática que torna necessária uma ação em si contingente; o imperativo categórico pres- 
creve uma ação, não como meio de atingir um certo fim, mas imediatamente, como que sendo objetivamente necessária.

A única ciência prática que contém tais imperativos é a ciência dos costumes, isto é: a moral.

Todos os outros imperativos são técnicos e condicionais.

A liberdiade que não é limitada por nenhum imperativo contrário, toma o nome de direito.

Estes dois conceitos, o da liberdade e o da obrigação, aproximados, implicam um terceiro conceito, o da universalidade.

E' da essência de uma coisa livre ser racional; um ser racional, fundando em sua essência sua lei e seu fỉm, não póde nela achar senão uma lei aplicável a todo o ser racional e livre e, portanto, universal.

Assim, um dos caracteres necessários da lei é a universalidade, isto é: o de poder universalizar e ser concebida pela razão como obrigando todos os seres racionais possiveis.

O imperativo categórico se formula assim: "Age segundo uma regra que possa ter ao mesmo tempo o valor de uma lei universal".

Uma proposição contendo um imperativo categórico ẻ uma lei.

KANT reconhece que a nossa vontade é solicitada por diferentes motivos, tais como o prazer, a simpatia ou antipatia, o temor dos castigos da outra vida; mas, nenhum destes motivos póde ser erigido em máxima universal, porque nem todos se determinam pelo prazer, pela simpatia ou antipatia, pelo temor das penas futuras; e, portanto, estes motivos não pódem constituir base de uma lei universal.

A razão concebe $a$ priori o bem e o mal, assim como tambem percebe $a$ priori que o bem merece felicidade e o mal merece infelicidade ou sofrimento; mas acontece que, no mundo atual, nesta vida, os fatos não correspondem a isto, e, quando correspondem, não satisfazem todo o desejo de felicidade; segue-se, portanto, que ha uma outra vida e daí resulta a imortalidade da alma, como rigorosa dedução da moral. 
KANT chama soberano bem, a aliança na outra vida, da felicidade e do bem; e, desde que o estado atual das coisas exige uma série para a conexão necessária, concebida a priori pela razão, entre o bem moral e a felicidade, é necessário que haja um ente soberanamente perfeito que realize esta conexão, isto é: Deus; e daí resulta a existência de Deus, como outra dedução rigorosa da moral, isto é: da razão prática.e que, assim como a outra, KANT não achou meio de demonstrar na "Crítica da Razão Pura".

$\mathrm{Na}$ moral, em geral, o imperativo categórico é aquele que ficou formulado; mas, o direito é um conceito que os restringe ás relações externas de uma pessôa para com outra, enquanto suas ações pódem ter, como partes, influência umas sôbre as outras.

O direito é, pois, o complexo de condições por meio das quais o livre arbítrio de um póde estar de acôrdo com o livre arbítrio de outro, segundo uma lei geral de liberdade.

Eis o imperativo categórico do direito: "Age exteriormente de tal sorte que o teu livre arbítrio possa coexistir com a liberdade de todos, segundo uma lei geral".

$O$ injusto é um uso da liberdade, que não está de acôrdo com a lei geral; a coação oposta a êsse uso da liberdade contrário á lei geral, é a natural resistência ao obstáculo oposta á liberdade não contrária á lei geral, isto é: ao direito.

O direito implica, pois, a faculdade de constranger áquele que o perturba em vida.

\section{BENTHAM}

A natureza colocou o homem sob o império do prazer e da dôr, diz EpIcuro; o bem consiste no prazer, e o mal consiste na dôr.

Mas, o prazer não é a volúpia do momento assim como a dôr não é o sofrimento do momento, porque ha volúpias das quais nasce a dôr e sofrimentos dos quais nasce o prazer.

Por isso, o próprio EPICURo tendo em vista o futuro, estabeleceu a seguinte regra moral: "Evitai o prazer do qual 
vos possa resultar numa dôr e suportai a dôr que possa gerar um prazer superior".

A doutrina do prazer ficou assim, diz Bentham, substituida pela doutrina da utilidiade.

Utilidade é a tendência de uma coisa ou ação para preservar o mal e prevenir o bem; mal é a dôr ou causa da dôr; bem é o prazer ou causa do prazer.

Aquilo que tende a aumentar a soma total do bem estar de um indivíduo, - é conforme a utilidade do indivíduo, aquilo que tende a aumentar a soma total do bem estar dos indivíduos que compõem uma comunidade, - é conforme ao interesse geral.

A utilidade geral é o princípio do raciocínio em legislação, isto é: para ser o direito convertido em lei.

Ao princípio de utilidade se opõem o principio de ascetismo e o princípio de simpatia e antipatia.

O princípio de ascetismo funda a moral sôbre as privações e a virtude sôbre a renúncia de si mesmo; os estóicos disseram que a dôr não é um mal; os jansenistas chegaram a dizer que o prazer é um mal e a dôr um bem; outros mais moderados reconhecem que a dôr e prazer pódem ser um mal e um bem, conforme seus efeitos, porque ha atos de prazer dos quais sempre ou quasi sempre resulta a dôr, e dôres das quais póde resultar o prazer.

Em todo o caso, mesmo os ascéticos, suportando a dôr, o fazem para seguir a felicidade futura, isto é: a felicidade eterna e, portanto: por utilidade.

O princípio de simpatia e antipatia consiste em aprovar ou censurar por sentimento: uma ação é bôa ou má não porque agrada ou desagrada aquele que a pratica, mas porque ela agrada ou desagrada aquele que a julga.

Um funda o seu juizo no que ele chama conciência ou senso moral, outro, no que ele chama - senso comum, outro na ordem natural, etc.; mas, todos estes, diz Bentham, fundam-se no princípio de simpatia e antipatia, mascarado sobre diversas fórmas. 
Contudo, este princípio quasi sempre coincide com o princípio de utilidade, porque ter afeto ao que nos é útil e aversão ao que nos é nocivo, é uma disposição universal.

A moral e a jurisprudência levadas por este instinto quasi sempre atingem a utilidade.

Entretanto as simpatias e antipatias não são guias seguros.

Mesmo a antipatia póde se achar unida ao princípio de utilidade, v. g.: quando por simples ressentimento, se processa um ladrão perante os tribunais.

São estes os pontos fundamentais da Escola de Bentham.

Para desenvolvê-los e torná-los práticos, Bentham julga necessário achar um meio de avaliar a quantidade de bem e a quantidade de mal que emanam de uma ação, relativamente, ou fazer ver a dôr que dela resulta.

E' o que chamam - aritmética moral de Bentham - e que consiste em enumerar e classificar as diferentes espécies de prazeres e de dores e em determinar o valor comparativo das diferentes dores e dos diferentes prazeres, sob as seguintes relações :

$1^{\circ}$ - Em relação á intensidade, porque ha prazeres que são mais vivos e outros que o são menos;

$2^{\circ}$ - Em relação á duração, porque ha prazeres que se prolongam e outros que duram pouco;

3. ${ }^{\circ}$ - Em relação á certeza, porque os prazeres são futuros, isto é, em consequência de uma ação;

4. - Em relação á proficuidade, porque ha prazeres que resultam imediatamente da ação, ha outros que se manifestam muito tempo depois da ação;

$5 .^{\circ}-$ Em relação á fecundidade, porque ha prazeres que produzem outros;

$6^{\circ}$ - Em relação á pureza, porque ha prazeres que não geram dôres e ha prazeres cujas consequências são mais ou menos penosas. 
Mas, além disso, entra na avaliação dos prazeres e das dôres: o sexo, a idade, a profissão, o clima, a raça, a natureza do govêrno, a crença religiosa e outras circunstâncias gerais, assim como circunstâncias individuais, tais como: o temperamento, a educação, etc.

Ora, ha atos cujas consequências agradaveis ou desagradaveis derivam naturalmente das ações que praticamos: é a sanção natural; ha atos cujas consequências agradaveis ou desagradaveis atraem o desprêzo e a inimizade de nossos similhanties: é a sanção moral; ha atos cujas consequências agradaveis ou desagradaveis, conforme a nossa fé, nos acarretam recompensas e punições na outra vida: é a sanção religiosa; ha atos agradaveis ou desagradaveis para o indivíduo que impõem ao interesse de todos a imposição das penas ou recompensas nesta vida: é a sanção legal.

O fim da sociedade é o bem de todos os indivíduos; para isso o legislador tem de verificar si o mal da ação póde ser impedido ou ao menos prevenido pelo mal dar pena, e si o mal da pena em relação ao bem comum, é menor do que o mal da ação.

Verificada a afirmativa, é direito erigir a ação em delito e ligar-lhe uma pena, porque nisto está a utilidade geral.

Tal é a solução de Bentham.

Bentham, fundando o Direito, na utilidade, confunde o meia com o fim, isto é: não considera, na ação humana, um fin mas um meio.

O util não é uma substância nem uma qualidarde, o util é uma relação.

O homem póde agir por amor de si; mas, em regra, mesmo quando não age por amor de Deus, age por amor de si ou por amor dos outros, não só mediante o prazer como tambem mediante a dôr, tendo em vista a ordem das relações essenciais do homem, uns para com os outros, isto é: a lei moral, cujo primeiro princípio é a conservação da ordem natural e cujos primeiros preceitos são - fazer o bem, isto 
é: praticar atos que conduzam ao fim último, que é a felicidade eterna, evitai o mal, isto é: não praticar atos que perturbem a ordem natural e que privem de chegar a este fim.

O direito é realmente uma atividade pessoal util, porém, não só util, mas util e lícita, fundada na lei moral, que póde ser sancionada pela coação ou pela penalidade, isto é: pela força do poder público; e nisto sómente se distingue, mas não se separa, da moral ou ética geral.

Para Bentham a lei é um mal, porque sempre restringe a liberdade; mas é um mal necessário, porque é um remédio contra um mal maior, que é a falta de segurança social.

A segurança social é util á subsistência dos indivíduos, á abundância de produtos, á igualdade de todos no meio da ação.

Desta utilidade decorre a legitimidade das regras do direito civil, que garantem a propriedade e o cumprimento das obrigações mediante a coação. 